\title{
Article
}

\section{The T/Tn-Specific Helix pomatia Lectin Induces Cell Death in Lymphoma Cells Negative for T/Tn Antigens}

\author{
Mathias Simplicien ${ }^{1}\left(\mathbb{D}\right.$, Annick Barre ${ }^{1}{ }^{\oplus}$, Yamina Benkerrou ${ }^{1}$, Els J. M. Van Damme ${ }^{2}{ }^{\oplus}$, Pierre Rougé ${ }^{1}$ \\ and Hervé Benoist ${ }^{1, *}$ \\ 1 UMR 152 PharmaDev, Institut de Recherche et Développement, Faculté de Pharmacie, Université Paul, \\ Sabatier, F-31062 Toulouse, France; mathias.simplicien@univ-tlse3.fr (M.S.); annick.barre@univ-tlse3.fr (A.B.); \\ yamina.benkerrou@gmail.com (Y.B.); pierre.rouge.perso@gmail.com (P.R.) \\ 2 Department of Biotechnology, Faculty of Bioscience Engineering, Ghent University, B-9000 Ghent, Belgium; \\ elsjm.vandamme@ugent.be \\ * Correspondence: herve.benoist@ird.fr
}

check for updates

Citation: Simplicien, M.; Barre, A.; Benkerrou, Y.; Van Damme, E.J.M.; Rougé, P.; Benoist, H. The

$\mathrm{T} /$ Tn-Specific Helix pomatia Lectin Induces Cell Death in Lymphoma Cells Negative for T/Tn Antigens. Cancers 2021, 13, 4356. https:// doi.org/10.3390/cancers13174356

Academic Editor: Christoph F. A. Vogel

Received: 31 July 2021

Accepted: 25 August 2021

Published: 28 August 2021

Publisher's Note: MDPI stays neutral with regard to jurisdictional claims in published maps and institutional affiliations.

Copyright: (c) 2021 by the authors. Licensee MDPI, Basel, Switzerland. This article is an open access article distributed under the terms and conditions of the Creative Commons Attribution (CC BY) license (https:/ / creativecommons.org/licenses/by/ $4.0 /)$.
Simple Summary: Changes in glycosylation, such as incomplete synthesis and higher density of $O$-glycans on the cell surface, are frequently observed in cancer cells. Several types of truncated $O$ glycan structures, e.g., $\mathrm{T} / \mathrm{Tn}$ antigens, are suspected to disrupt molecular interactions between tumor microenvironment and immune cells, for instance, facilitating cancer immune-escape. Therefore, numerous exogenous lectins targeting aberrant $\mathrm{O}$-glycans are interesting tools for cancer diagnosis, prognosis, and therapy. However, the ability of exolectins to detect subtle alterations in the glycome of tumor cells and to interfere in tumor/healthy cell interactions remains largely unknown. The present article reports for the first time that the Helix pomatia (HPA) lectin, a well-known T/Tn-specific lectin, currently used as a tool in cancer diagnostics, kills Tn-positive leukemia cells and Tn-negative lymphoma cells but does not affect healthy lymphocytes. Thus, HPA could be used to discriminate between tumor and healthy cells, and detect subtle alterations in the glycosylation profile.

Abstract: Morniga G is a T/Tn-specific lectin, inducing cell death in Tn-positive leukemias but not in healthy lymphocytes. Helix pomatia lectin (HPA) is another T/Tn-specific lectin, currently used as tool for cancer diagnostics. The HPA-mediated tumor cell death was evaluated on human leukemia and mouse lymphoma cells, and compared to the effect of Morniga G. Both lectins induced an equivalent percentage of cell death in Tn-positive Jurkat human leukemia. In contrast, EL4 mouse lymphoma resisted Morniga G-mediated cytotoxicity but were killed by HPA at concentrations of $2.5 \mu \mathrm{g} / \mathrm{mL}$ $(0.032 \mathrm{nM})$ and higher. In both malignant cells, HPA-mediated cell death showed features compatible with apoptosis (annexin-externalization, caspase-activation, mitochondrial membrane depolarization, and ROS production). Cytometry analysis indicated that EL4 cells are T/Tn-negative. Because previous results showed a high amount of $N$-acetylgalactosamine (GalNAc, sugar present in $\mathrm{Tn}$ antigen) on EL4 cell surface, this GalNAc could be involved in the formation of truncated $O$-glycans other than the $T / T n$ residues. When compared to Morniga $G$, bioinformatic analysis suggested that HPA benefits from an extended carbohydrate-binding site, better adapted than Morniga G to the accommodation of more complex branched and truncated O-glycans (such as core 2). Finally, HPA killed EL4 cells but not healthy lymphocytes in a mixture of lymphoma cells + lymphocytes, suggesting that HPA selectively triggers tumor cell death.

Keywords: lectins; T/Tn antigens; T lymphoma; truncated O-glycans; cancer cell death; Helix pomatia agglutinin; Morniga G; leukemia; biomedical applications

\section{Introduction}

Dramatic changes in the glycosylation profile of membrane molecules are one of the obvious characteristics of cancer cells [1,2]. These changes involve glycolipids and 
glycoproteins, for instance the $\mathrm{N}$ - and/or O-glycosylation of proteins. Among the possible modifications, three main changes are frequently observed in proteins: (i) an increase of $\mathrm{N}$ glycan branching mediated mostly by $\beta 1,6-\mathrm{N}$-acetylglucosamine transferase 5 (MGAT5) [3], (ii) an aberrant $O$-glycan synthesis resulting in the expression of a large quantity of truncated glycans on the tumor cell membranes, such as the over-expression of Tn antigen (GalNac $\alpha$ Ser/thr) [4-6], and (iii) a hypersialylation [7]. The presence of aberrant glycosylation can be demonstrated in a majority of cancers, both in solid tumors and in hematological malignancies, e.g., [8-10]. Some changes in the glycan patterns are used as diagnostic or prognostic markers $[7-9,11]$ and some can serve as therapeutic targets $[1,7,12]$.

The presence of aberrant glycosylation is one of the consequences of the genetic and epigenetic abnormalities that accompany carcinogenesis [2]. The alteration of the cancer cell glycosylation is not only a result of the pathological cancer processes, it can have functional consequences strongly implicated in cancer pathophysiology. Some of these alterations participate in tumor growth and migration, the appearance of metastasis, and the escape of tumors to anti-cancer immune response $[5,7,13]$. Thus, certain modifications of glycosylation could facilitate the cancer-cell resistance to death induced by various immunological effectors (e.g., cytokines and killer cells). For instance, alterations of the $\mathrm{N}$-glycosylation of Fas ligand receptor (CD95) or the O-glycosylation of Trail-receptor (TRAIL-R1 and TRAIL-R2) could modulate the tumor cell death triggered by FasL or TRAIL, respectively, thus participating in tumor escape. For instance, the normal $O$-glycosylation of TRAIL-R2 (DR5) [14-16] and the N-glycosylation of TRAI-R1 (DR4) [17] seem essential for efficient triggering of TRAIL-mediated apoptosis. Consequently, alterations in the glycosylation of TRAIL/FasL receptors present on the tumor cell surface could be involved in the dysregulation of immune surveillance against tumor cells.

In healthy conditions, animal glycome participates in tissue homeostasis. Many molecules are able to interact with glycome and help to maintain homeostasis. Emerging evidence indicates that glycan molecules encode biological information that can be recognized and translated with use of glycan-binding proteins (GBPs). Lectins are a major group of GBPs characterized and defined by the presence of carbohydrate-recognizing domains (CRDs). To date, in animals and humans, several endogenous lectins have been clearly implicated in a variety of physiological and pathological processes, e.g., the C-type lectins, the galectins, and the I-type lectins (Siglecs and others) [18,19].

Among GBPs, the plant lectins are exogenous molecules that can specifically recognize glycan patterns in animals, and have been considered for a long time as useful glycan probes to analyze healthy or pathological glycan patterns, e.g., for the diagnosis or prognosis of cancer $[20,21]$. Thus, several plant lectins specifically recognize aberrations in the glycosylation profile expressed by cancer cells and could be used to analyze the functional role of glycosylation in cancer cells [22-24]. In addition, because of their capacity to recognize specific glycans, plant lectins have been proposed as tools for targeting drugs towards pathological glycan patterns $[12,25]$. Numerous observations indicate that some plant lectins can induce cell death in cancer cells, only because of their binding to glycans on cell membrane glycoproteins or glycolipids, which in turn can trigger cell death pathways $[15,20,24,26]$, and not because of their intrinsic toxicity (in contrast to ricin and some other lectins from the R-type family, where the lectin subunits are known to be associated to a separate subunit possessing a potent intrinsic toxin activity). However, although lectin binding on the cells is necessary to induce cell death, it is not sufficient to provoke apoptosis, suggesting that the lectin effects on cells depend, at least partly, on the cell membrane protein (or the lipid) carrying the glycans recognized by the lectin.

$O$-glycans are present on many glycoproteins. This posttranslational modification is characterized by the attachment of one GalNAc to a Ser or Thr, followed by the formation of linear or branched chains with variable length and composed of different sugars, except for Man and Glc. T (Gal $\beta 1-3 G a l N A c \alpha$ Ser/Thr) and Tn (GalNAc $\alpha$ Ser/Thr) glycotopes are among the most abundant truncated $O$-glycans observed on tumor cells. The T/Tn glyco- 
topes, together with other $O$-glycans aberrantly overexpressed on cancer cells, represent cancer-markers as well as potential therapeutic targets [4-6,12].

Among the numerous plant lectins known to recognize Tn antigen, Morniga $G$ is a tetrameric lectin belonging to the subfamily of galactose-binding jacalin-related lectins isolated from black mulberry (Morus nigra) [27].

$\mathrm{H}$-type lectins are a group of exogenous lectins occurring in invertebrates, such as Helix pomatia, but also present in higher fungi and microorganisms. These lectins are mainly GalNAc-specific. The Helix pomatia agglutinin (HPA) is a hexameric glycoprotein known to be Tn-specific. HPA binding to cancer cells can be associated with metastatic invasion and poor patient prognosis [28].

Recently we demonstrated that Morniga G can interact with Tn antigen present on Jurkat human leukemia, inducing tumor cell death but not death of Tn-negative healthy peripheral blood lymphocytes, at least partly via the TRAIL/DR5-dependent pathway [15]. The increase of Tn epitopes on strategic molecules such as DR5 could be involved in the resistance of tumor cells to TRAIL-induced cell death [14-17].

The lectin from Helix pomatia is used in diagnostics for several human carcinomas [11,29-32]. However, to our knowledge very little information is known about the putative functional role of HPA-binding glycoproteins on tumor cells. In the present paper, we demonstrate for the first time that HPA induces cell death in human Jurkat T-cell leukemia and mouse EL4 T-cell lymphoma. In the mouse, HPA is clearly more toxic than Morniga G for EL4 cells. In addition, HPA appears to be non-toxic for healthy lymphocytes.

\section{Results}

\subsection{HPA Kills In Vitro the Tn-Positive Jurkat T-Cell Leukemia}

To explore the possibility that HPA activates cell death pathways, its toxic effect on Jurkat Tn-positive cells was evaluated and compared to the effect of MorG, previously demonstrated to be able to kill Jurkat cells. As expected, HPA binds to Jurkat T-cells with similar efficiency to Morniga G, as observed in cytometry analysis (Figure 1A). More interesting, using previous experimental conditions defined to induce optimal Morniga G-mediated cell death in Jurkat leukemia, HPA triggers similar cell apoptosis (Figure 1B), caspase activation (Figure 1C), and depolarization of mitochondrial membrane potential (Figure 1D). However, the lectin-mediated toxicity on T leukemia cells was not observed with the mannose (Man)-specific lectin Artocarpin (Figure 1B-D), in spite of its binding to Jurkat T-cells. Finally the ROS production was evaluated, and compared to that observed during T-cell activation by ConA. ConA is a Glc/Man-specific lectin known to cross-link $\mathrm{T}$-cell receptors and activate $\mathrm{T}$ cells, such as Jurkat cells. HPA already triggers a strong ROS production after $30 \mathrm{~min}$ incubation with tumor cells, and this effect is higher than the ROS-induction mediated by ConA (Figure 1E).

\subsection{HPA Kills T/Tn-Negative EL4 T-Lymphoma Cells}

Recently it was demonstrated that murine EL4 cells exhibited higher levels of GalNAc than normal T cells [33], suggesting that these cells could be possible targets for HPA and Morniga G. Cytometry analysis indicated that both lectins bind to EL4, similarly to the Glc/Man-specific lectin ConA (Figure 2A). However, no staining of EL4 was observed with anti-Tn (anti-GalNAc $\alpha$ Ser/Thr antigen) monoclonal antibody (Figure 2A). Analysis of the concentration-dependent effect in in vitro experiments indicated that only HPA induced significant EL4 cell death at a concentration of $2.5 \mu \mathrm{g} / \mathrm{mL}$ after $48 \mathrm{~h}$ incubation. Data were compared to Morniga G, used as a T/Tn-specific lectin control, and ConA, used as a negative control (Figure 2B). In addition, HPA-treated cells showed classical apoptosis features such as annexin positivity (Figure 2B), caspase activation (Figure 2C), mitochondrial-membrane potential depolarization (Figure 2D), and characteristic morphological alterations (e.g., nuclear fragmentation and condensation) (Figure 2E). In addition, an increase in cell size was observed in some HPA-treated cells, suggesting that the lectin binding could also induce different cell-death pathways simultaneously in the EL-4 cell 
population (Figure 2E). Finally HPA treatment induced a high ROS signal in EL4 cells, which was compatible with triggering of various processes of programmed cell death (Figure 2F). In conclusion, all the results indicate that the Gal/GalNAc-specific HPA provokes strong cell death in EL4 cells as compared to Morniga G, another Gal/GalNac-specific lectin, whereas ConA does not kill cells in spite of strong binding to the tumor cells.

A

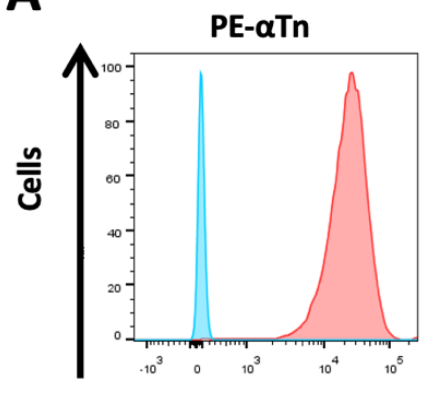

FITC-HPA

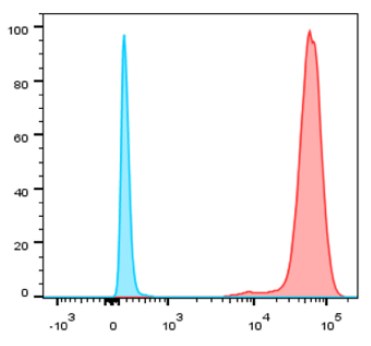

FITC-MorG

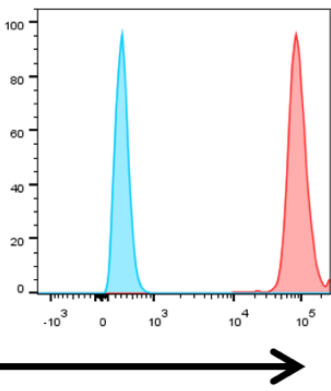

Fluorescence intensity

B

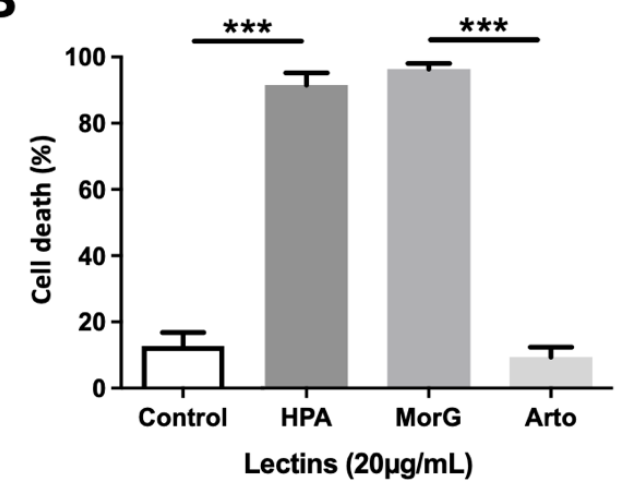

C
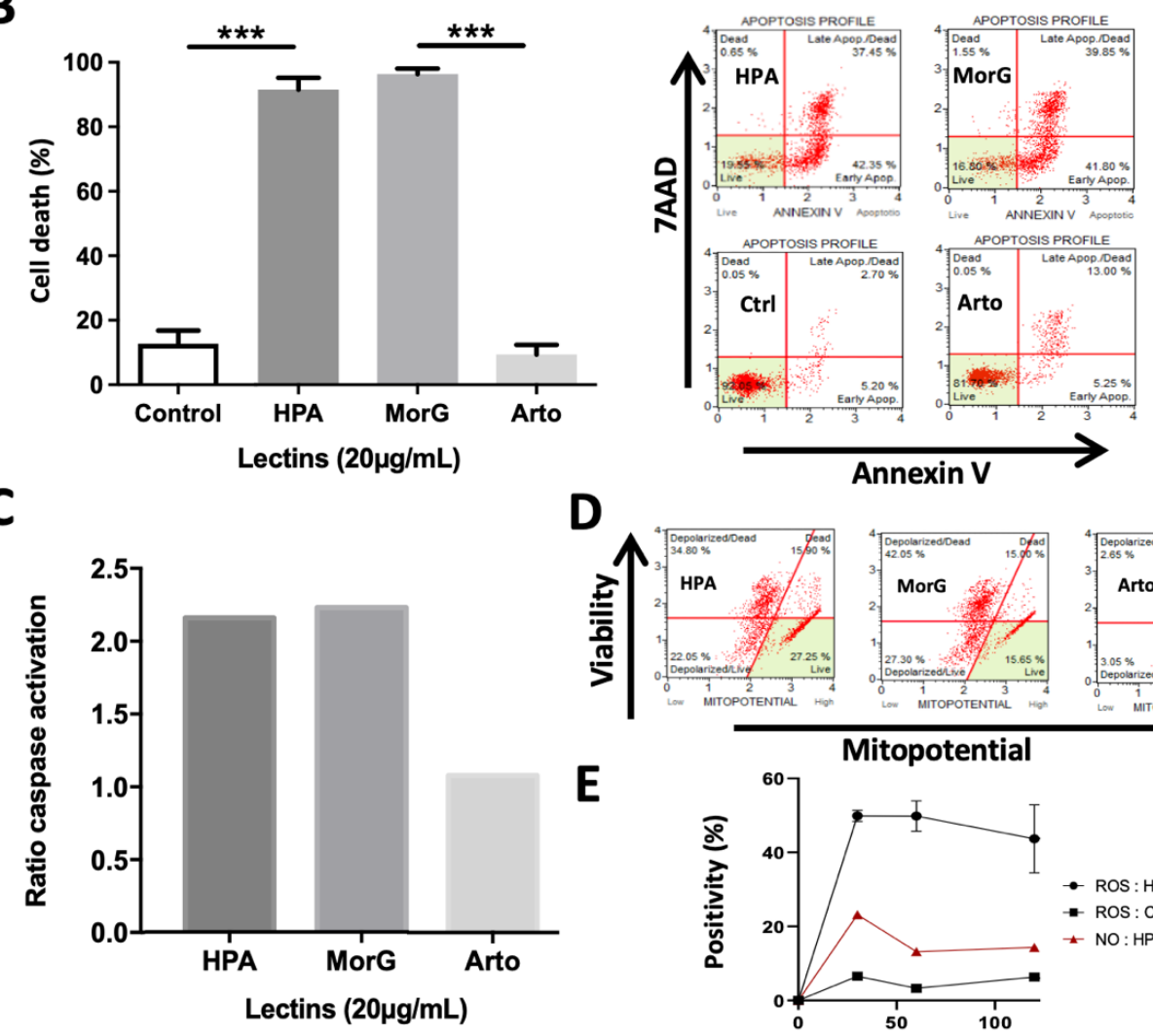

D

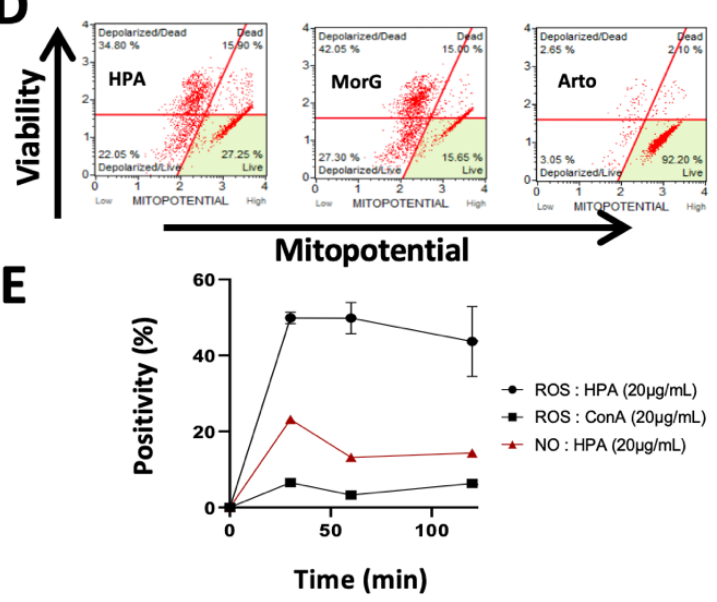

Figure 1. HPA induces cell death in human T-leukemia cells: (A) Jurkat A3 leukemia cells were labeled with anti-Tn mouse monoclonal antibody (PE- $\alpha$ Tn), FITC-conjugated HPA (FITC-HPA), or FITC-conjugated Morniga G (FITC-MorG), and analyzed using cytofluorimetry (blue curves indicate cell autofluorescence). (B-D) Leukemia cells were cultured for $48 \mathrm{~h}$ in the presence of $20 \mu \mathrm{g} / \mathrm{mL}$ HPA, MorG, or Artocarpin (Arto), then analyzed by cytofluorimetry. (B) Specific cell death evaluated using Annexin V/7AAD assay, on the right: representative experiment; (C) caspase activation; and (D) mitochondrial depolarization, representative of two independent experiments. (E) Jurkat cells were cultured with $20 \mu \mathrm{g} / \mathrm{mL}$ HPA or Concanavalin A (ConA). Next, reactive oxygen species (ROS) or nitric oxide (NO) were evaluated at different times using cyto-fluorimetry. (B,C,E), Results are means \pm SD of at least three independent experiments or means of two independent experiments. Significant differences are indicated $(* * *<0.001)$. 
A

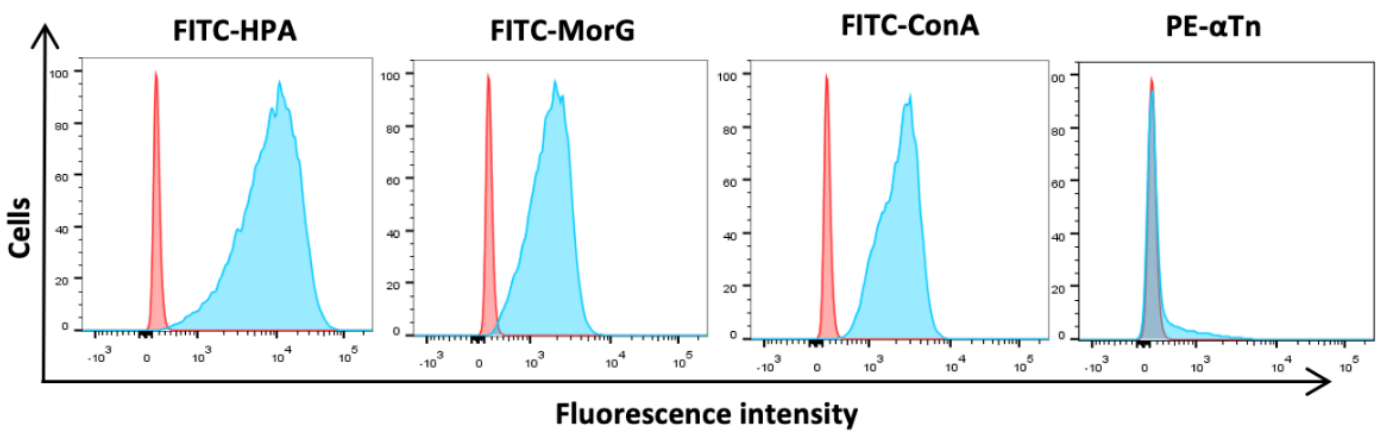

B
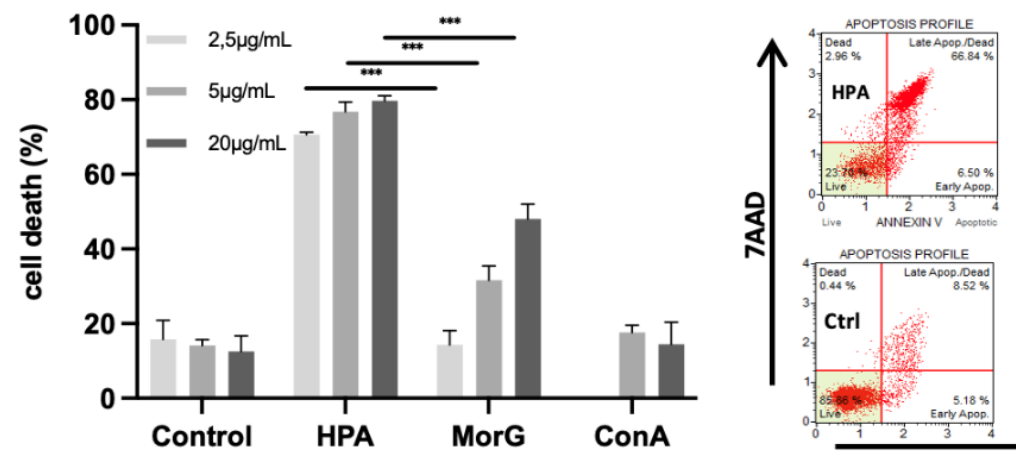

C
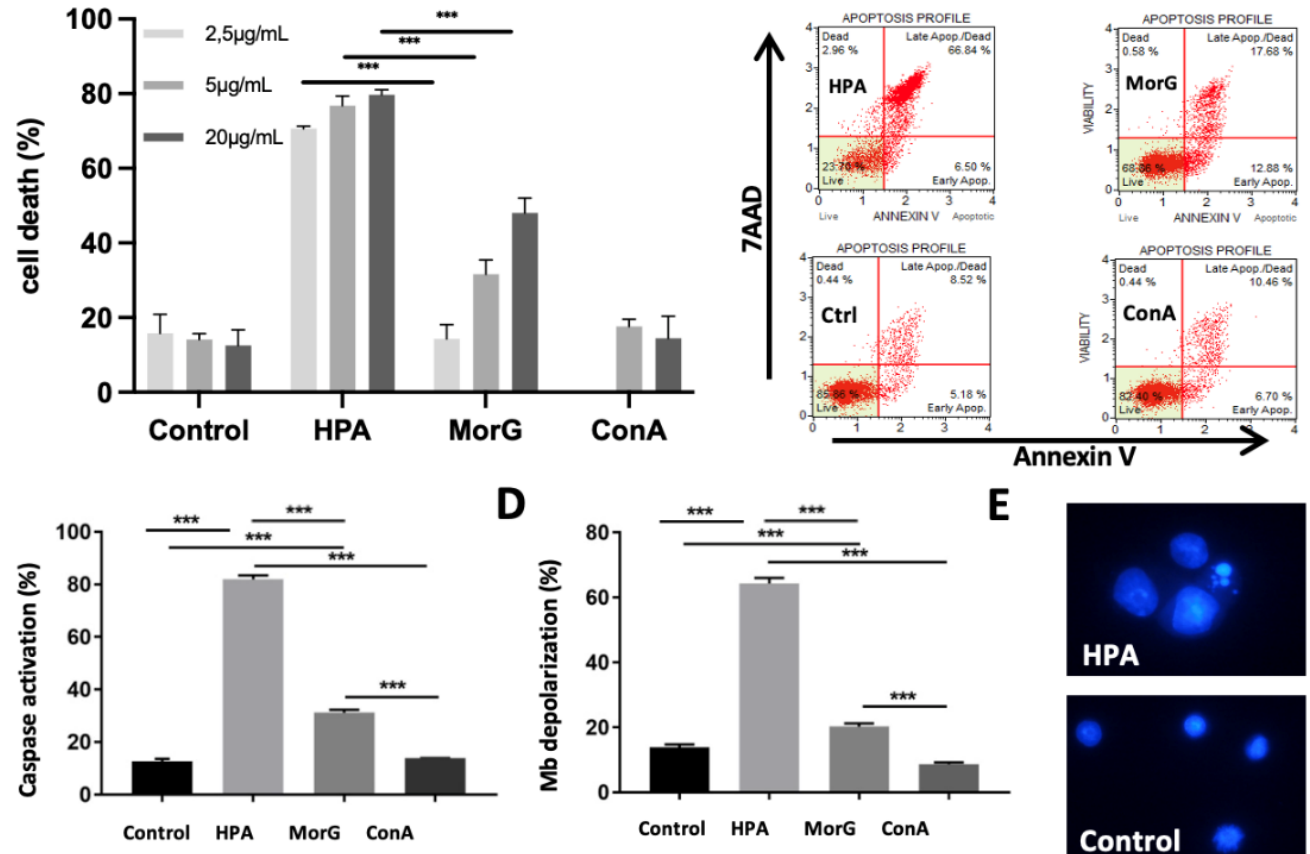

\section{Annexin V}

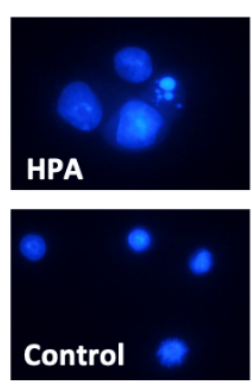

$\mathbf{F}$

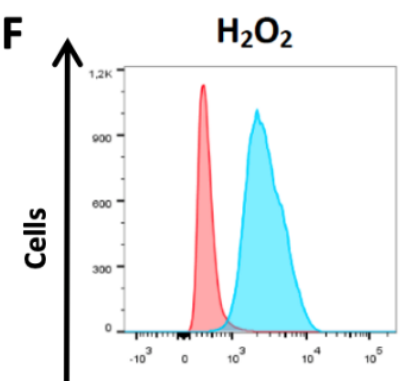

$20 \mathrm{~min}$

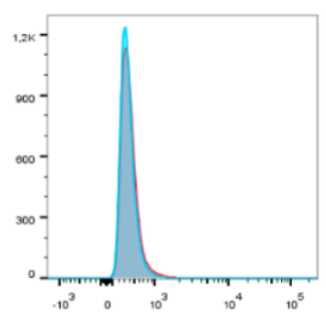

$30 \mathrm{~min}$

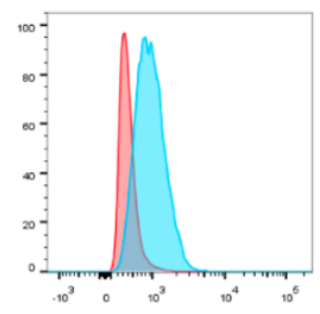

$60 \mathrm{~min}$

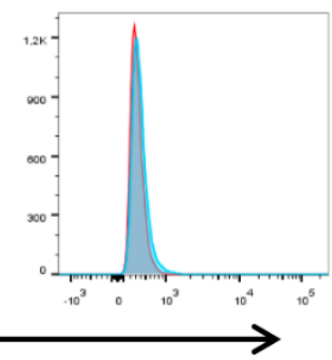

Fluorescence intensity

Figure 2. HPA induces cell death in mouse T-lymphoma cells: (A) EL4 lymphoma cells were incubated with anti-Tn mouse monoclonal antibody + PE anti-mouse antibody (PE- $\alpha$ Tn), FITC-conjugated HPA (FITC-HPA), FITC-conjugated Morniga G (FITC-MorG), or FITC-conjugated ConA (FITC-ConA) and analyzed using cytofluorimetry (Red curves indicate autofluorescence). (B-D) EL4 lymphoma cells were cultured for $48 \mathrm{~h}$ with different concentrations of HPA, MorG, and ConA and analyzed using cytofluorimetry: (B) cell viability evaluated with Annexin V/7AAD assay (on the right, representative experiment), (C) caspase activation, and (D) mitochondrial membrane depolarization (C,D, lectin $5 \mu \mathrm{g} / \mathrm{mL}$ ). (E) Cellular morphology was observed after DAPI staining and using fluorescent microscopy, representative of three independent experiments. (F) EL4 cells were incubated for 20-50 min with $20 \mu \mathrm{g} / \mathrm{mL}$ HPA. Next, reactive oxygen species production was evaluated at different times using dihydroethidium assay in cytofluorimetry, as compared with $\mathrm{H}_{2} \mathrm{O}_{2}$ treatment $(0.1 \mathrm{mM}$, $20 \mathrm{~min})$. (B-D), results are means \pm SD of at least three independent experiments. Significant differences are indicated $(* * *<0.001)$. 


\subsection{HPA Induces Death in EL4 T-Cells but Not in Healthy T-Cells}

Because Morniga $G$ was shown to bind strongly to the Tn-positive Jurkat T-cell leukemia but not to healthy human peripheral blood lymphocytes [15], the binding of 0.01 to $1 \mu \mathrm{g} / \mathrm{mL}$ HPA was evaluated on murine lymphocytes (non-adherent splenocytes, i.e., NK, B, and T lymphocytes) and compared to EL4 cells. HPA did not stain NK, $\mathrm{B}$, or $\mathrm{T}$ lymphocytes (or very faintly at $1 \mu \mathrm{g} / \mathrm{mL}$ concentration, Figure $3 \mathrm{~A}$ ), whereas Morniga $G$ actually stained two distinct lymphocyte populations (Figure 3B). When a mixture of non-adherent splenocytes + EL4 cells was treated with HPA or Morniga G $(20 \mu \mathrm{g} / \mathrm{mL}, 48 \mathrm{~h})$, followed by cell death analysis using cytometry, it was observed that HPA killed EL4 cells more efficiently than Morniga G, whereas percentages of CD3+ and CD3- lymphocytes were increased significantly as compared to the control, likely mainly due to EL4 cell death. In the Morniga G-treated-mixture cells, only the percentage of CD3negative lymphocytes increased, suggesting that HPA and Morniga G have discrepancy effects on healthy lymphocytes (Figure 3C,D). Finally, HPA did not alter the viability of healthy lymphocytes after $24-48 \mathrm{~h}$ culture (Figure $3 \mathrm{E}$ ). Altogether, the results suggest that HPA efficiently discriminates between EL4 lymphoma cells and healthy lymphocytes, indicating that the lectin can recognize glycan structures on tumor cells which are underexpressed or absent on normal mouse lymphocytes.

\subsection{What Could Be the Targets of HPA on EL4 T-Lymphoma Cells?}

It was previously demonstrated that sialic acids are strongly expressed on EL4 cells as compared to normal T-cells [33]. To evaluate the putative role of sialic acids in HPA-induced cell death, the effect of sialidase treatment of EL4 cells was first evaluated with respect to binding of anti-T/Tn Mabs, HPA, Morniga G and ConA to EL4 cells (Figure 4A-C). Firstly, using cytometry analysis no staining of EL4 was observed with anti-T (anti-core 1 or anti-Gal $\beta 1-3 \mathrm{GalNAc} \alpha \mathrm{Ser} / \mathrm{Thr}$ ) antibody, indicating that EL4 cells are T negative cells (Figure 4A) and that core 1 is not a target for HPA. Secondly, the anti-Tn Mab binding was moderately increased by neuraminidase-treatment, suggesting that EL4 cells express sialyl-Tn or that sialic acids hinder the access of anti-Tn Mabs to Tn antigen (Figure 4A). In addition, as expected the binding of the three lectins was increased after sialidase treatment (Figure 4B,C). Finally the effect of sialidase pre-treatment was evaluated on lectin-induced cell death, but revealed no increase in cell death (Figure 4D), suggesting that sialic acid does not significantly alter the HPA-induced toxicity against EL4 T lymphoma.

Since previous data indicated that HPA can be GlcNAc-specific [34], a comparative bioinformatic analysis was performed to evaluate the GlcNAc binding capacity of HPA and Morniga G. GlcNAc appeared as a possible ligand for both lectins and results were very similar to GalNAc or Tn antigen (Figure 5). Because all above results indicated that Morniga G and HPA show different effects on lymphocytes and lymphoma cells (e.g., in their capacity to bind to lymphocytes and to induce cell death in EL4 cells), the structural differences between the two lectins are worth investigating, in order to find an explanation for the discrepancies observed. Although both lectins exhibited a very similar binding towards GalNAc and Tn antigen, they differed in their overall organization, the number and localization of the CRDs, and the topography of the molecular surfaces surrounding their monosaccharide-binding sites (MBS) (Figure 5). HPA consists of two homotrimers, each possessing three CRDs resulting in six CRDs (hexavalent lectin, [35]) (Figure 5A), whereas Morniga-G is a homotetramer that only contains four CRDs (tetravalent lectin) (Figure 5F). HPA contains three CRDs in each homotrimer, located close to each other $(\approx 27 \AA)$ at both ends of the lectin. In contrast CRDs are more separated in Morniga-G $(\approx 45 \AA$ ) (Figure $5 B, G)$. Accordingly, HPA should be better adapted than Morniga-G to induce the formation of TACA clusters on the cell surface. In addition to the recognition of simple sugars, the recognition of more complex $\mathrm{O}$-glycans (or $\mathrm{N}$-glycans) by HPA benefits from an extended carbohydrate-binding site, better adapted to the accommodation of branched O-glycans, compared to Morniga-G (Figure 6). In fact, the topography of the areas distributed around the MBS in HPA, offers more possibilities for a better accommodation of, for instance, $\alpha 1,2-$, 
$\alpha 1-4$, or $\alpha 1-6$-branched $O$-glycans due to the largely open configuration of the molecular surfaces surrounding the MBS (Figure 6A). In contrast, the molecular surfaces around the MBS of Morniga G are oriented on a single axis that prevents heavily branched O-glycans being properly accommodated by the extended binding site of the lectin [36] (Figure 6B). All these discrepancies occurring between both HPA and Morniga G, should account for a rather distinct behavior and binding to glycan structures on cancer cells.

A
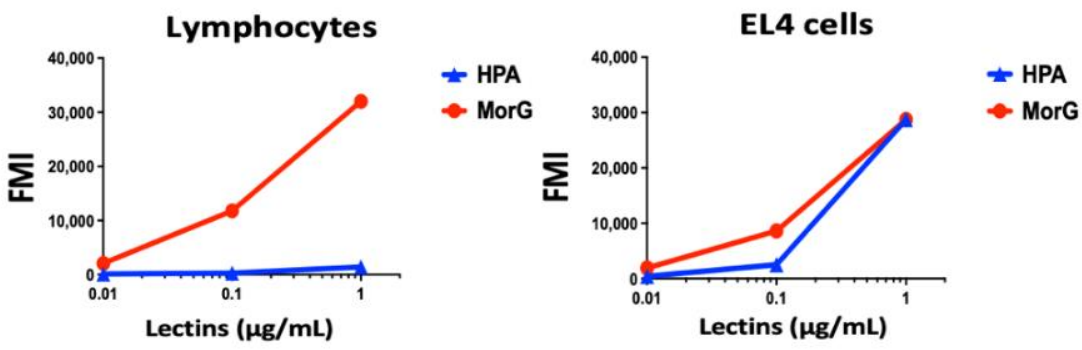

B

FITC-HPA
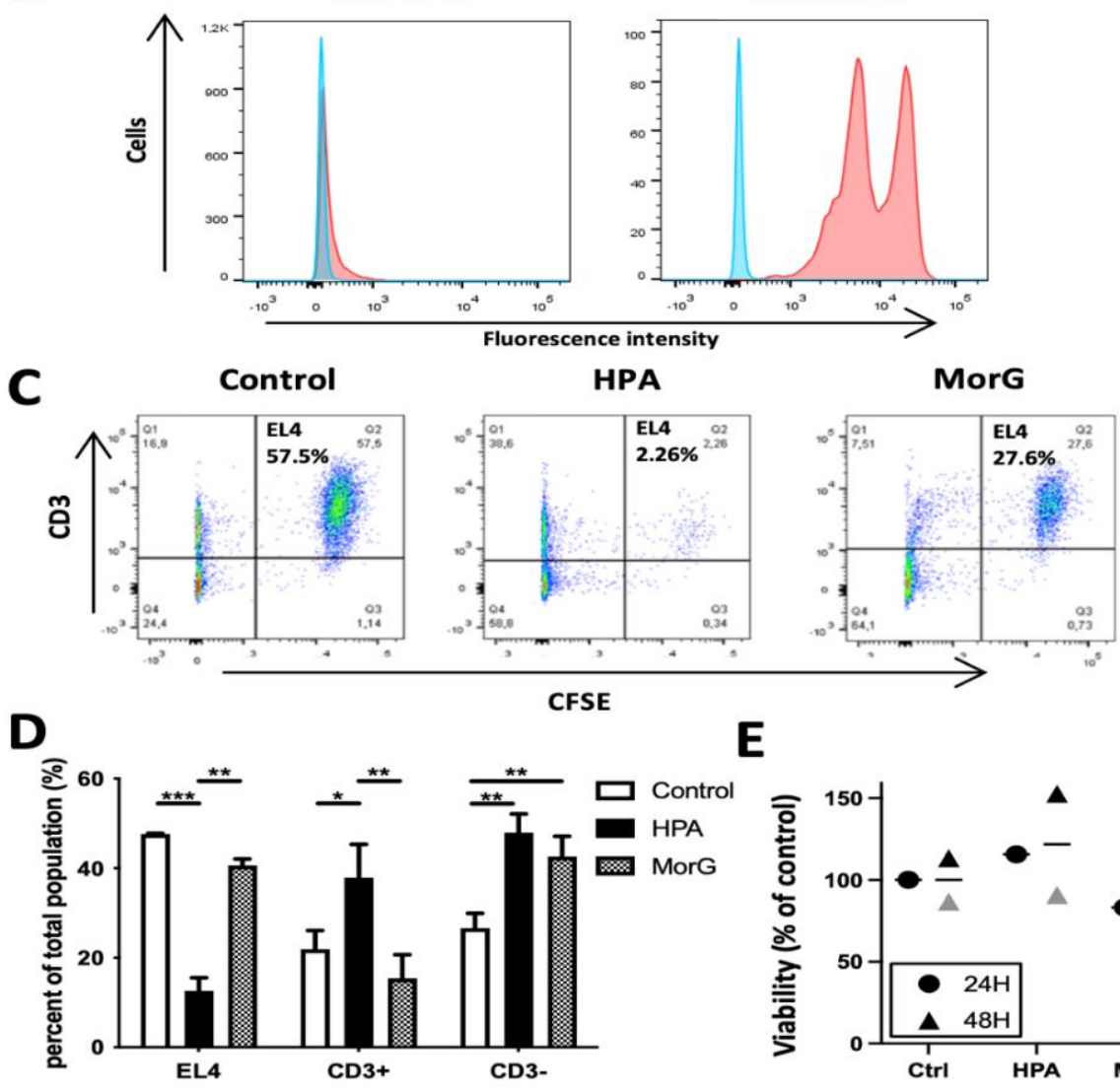

E

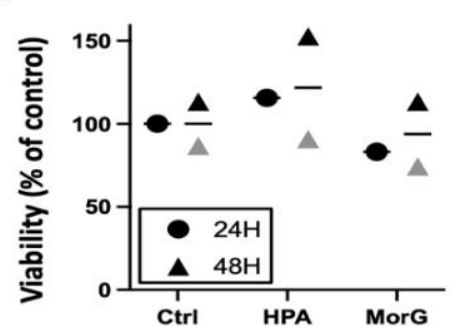

Figure 3. HPA induces a discriminative toxicity on EL4 tumor cells: (A,B) Non-adherent splenocytes from healthy mice (lymphocytes) or EL4 lymphoma cells were labeled by increasing concentrations of FITC-conjugated HPA (FITC-HPA) or FITC-conjugated Morniga G (FITC-MorG) and analyzed using cytofluorimetry. (B) Representative staining of healthy lymphocytes using $1 \mu \mathrm{g} / \mathrm{mL}$ FITC-HPA or FITC-MorG. (C,D) Mixture (1:1) of healthy lymphocytes and CFSE-labeled EL4 lymphoma cells were cultured for $48 \mathrm{~h}$ in the presence of $20 \mu \mathrm{g} / \mathrm{mL}$ HPA or MorG, washed and then incubated with PE-labelled anti-CD3 mouse monoclonal antibody and analyzed using cytofluorimetry: (C) representative experiment and (D) means of three independent experiments. (E) Lymphocytes from healthy mice were incubated for 24-48 $\mathrm{h}$ with $20 \mu \mathrm{g} / \mathrm{mL}$ HPA or MorG, then cell viability was evaluated using cytofluorimetry. Rounds and triangles are means of three to four mice. Horizontal lines are means of the two independent experiments after $48 \mathrm{~h}$ cultures. Significant differences are indicated $(* p<0.05 ; * *<0.01 ; * * *<0.001)$. 
A

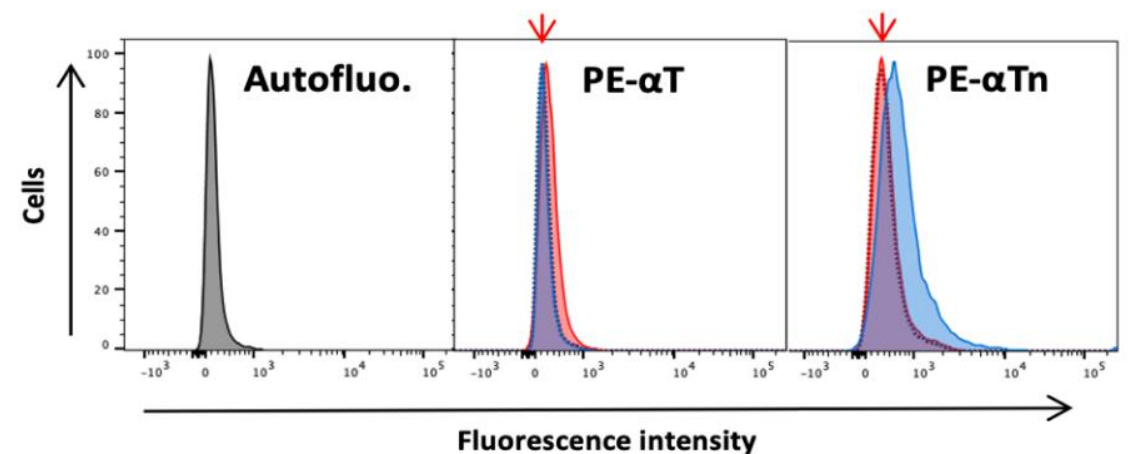

B

FITC-HPA

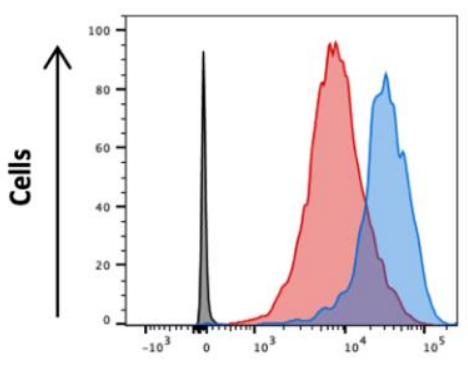

FITC-MorG

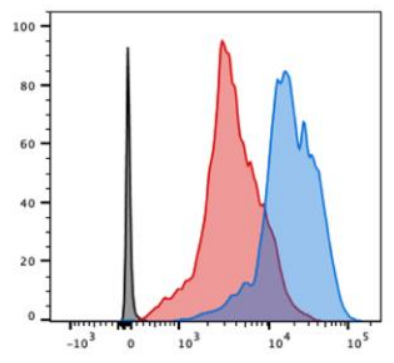

Fluorescence intensity
FITC-ConA

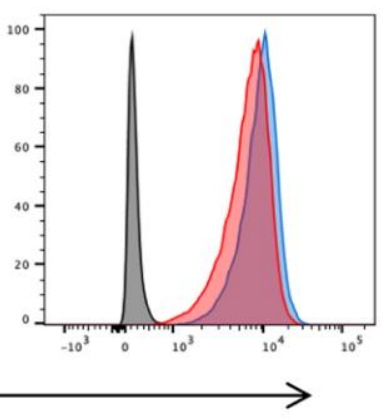

C
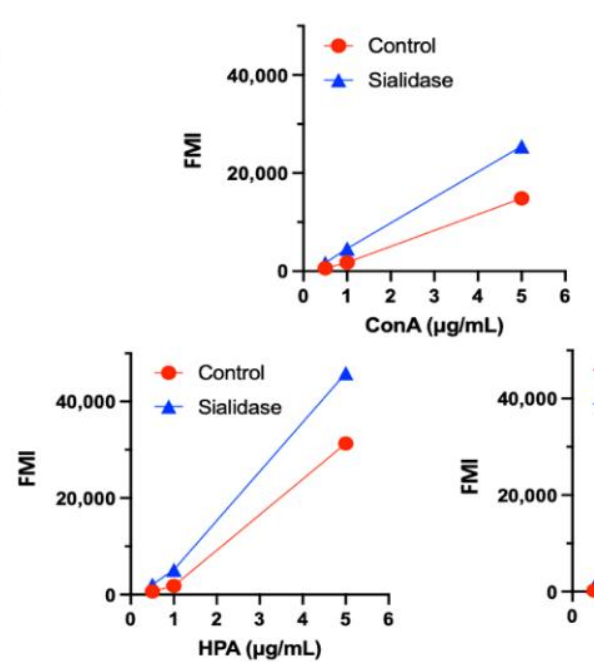

D
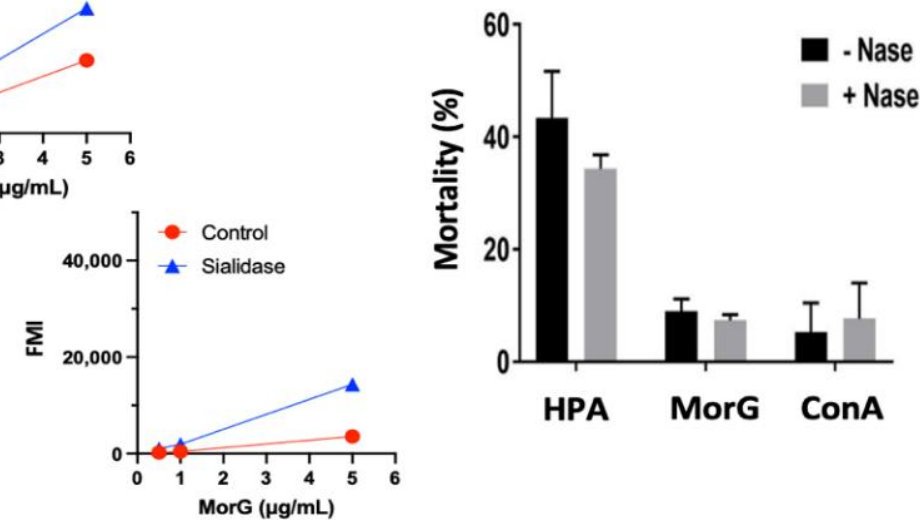

Figure 4. Effect of neuraminidase treatment on glycan detection at EL4 cell surface and lectin-induced cell death: (A-C) EL4 cells were incubated with (blue) or without (red) neuraminidase $\left(20 \mathrm{mUI}, 30 \mathrm{~min}, 37^{\circ} \mathrm{C}\right)$ and labeled: (A) with anti-Tn (PE- $\alpha \mathrm{Tn}$ ) or anti-T (PE- $\alpha \mathrm{T})$ mouse monoclonal antibodies or $(\mathbf{B}, \mathbf{C})$ with FITC-lectins: HPA (FITC-HPA), MorG (FITC-MorG), or ConA (FITC-ConA). (A) Red arrow indicates autofluorescence pic position (grey curve); (B) representative results of two independent experiments with $5 \mu \mathrm{g} / \mathrm{mL}$ of labeled lectin, with blue curve corresponding to neuraminidase-treated cells; and (C) lectin concentration effect on labelling. (D) EL4 cells were incubated with (+ Nase) or without (- Nase) neuraminidase, washed, and cultured for $48 \mathrm{~h}$ with $2.5 \mu \mathrm{g} / \mathrm{mL}$ of HPA, MorG, or ConA, then cell death was analyzed using cytofluorimetry. Results are means \pm SD of three independent experiments. 


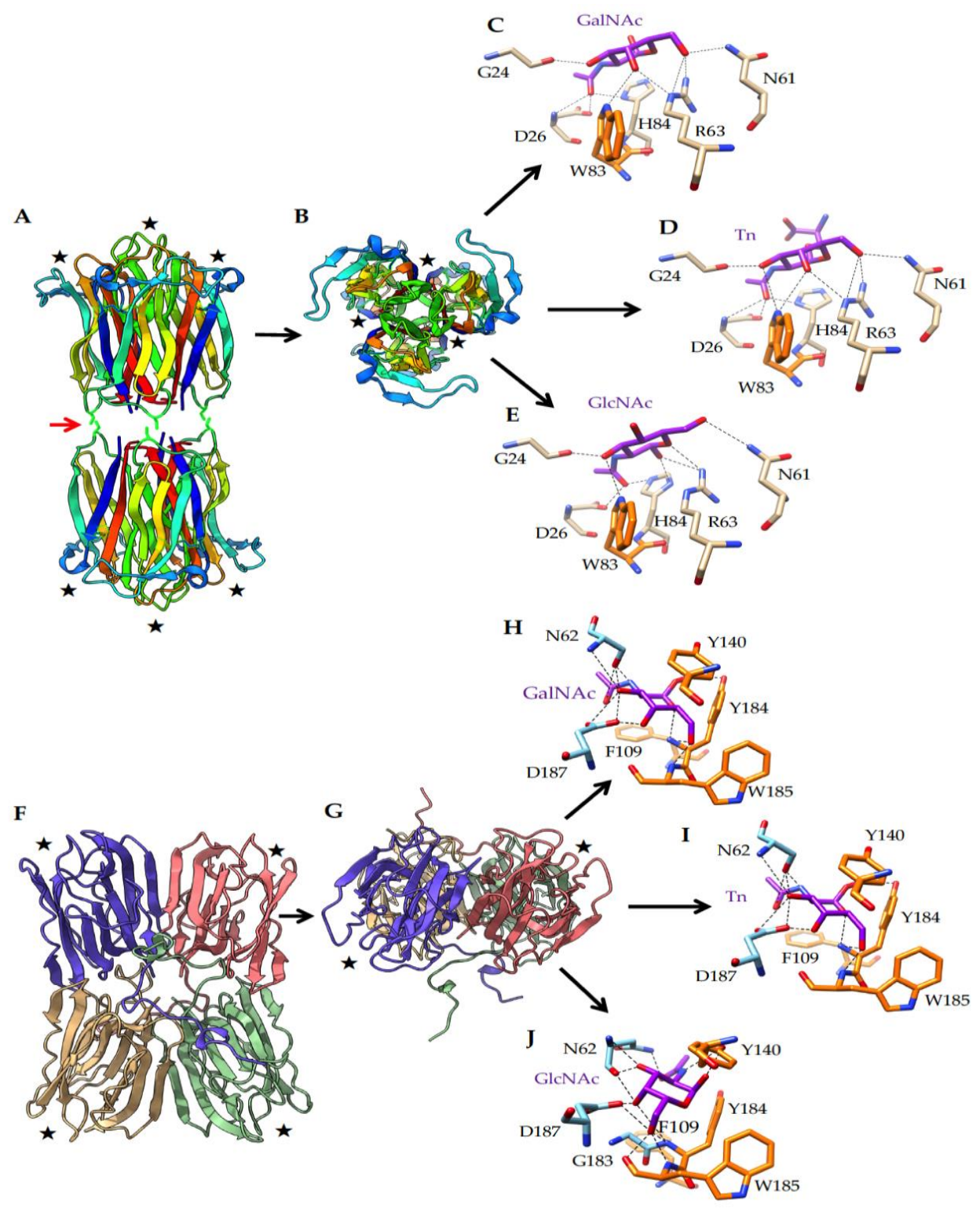

Figure 5. Comparative bioinformatic modeling of HPA and Morniga G: (A) Ribbon diagram of the overall three-dimensional structure of HPA hexamer, built from two homotrimers associated by three disulfide bridges. The cysteine residues involved in the association of the homotrimers in a hexameric structure are indicated by the red arrow. Black stars indicate the localization of the CBSs at the top of each homotrimer. (B) Front face of the HPA homotrimer showing the localization of the CRDs. (C-E) Docking of GalNAc (C), Tn antigen (D), and GlcNAc (E) to the monosaccharide-binding site (MBS) of HPA through a network of hydrogen bonds (back dashed lines) connecting hydrophilic amino acid residues forming the MBS to the sugars GalNAc and GlcNAc, and the sugar derivative Tn antigen. Aromatic residues (colored orange), located in the vicinity of the MBS, reinforce the interaction with the sugars by stacking interactions with the pyranose ring of the sugars. (F) Ribbon diagram of the overall three-dimensional model Morniga-G tetramer, built from the non-covalent association of four monomers, each containing one MBS (black star) located at the top of beta-prism monomer. (G) Front face of the Morniga-G homotetramer showing the localization of the CRDs. (H-J) Docking of GalNAc (H), Tn antigen (I), and GlcNAc (J) to the MBS of Morniga-G, via a network of hydrogen bonds (back dashed lines) connecting hydrophilic amino acid residues forming the MBS to the sugars GalNAc and GlcNAc, and the sugar derivative Tn antigen. Aromatic residues (colored orange), located in the vicinity of the MBS, reinforce the interaction with the sugars through stacking interactions with the pyranose ring of the sugars. 

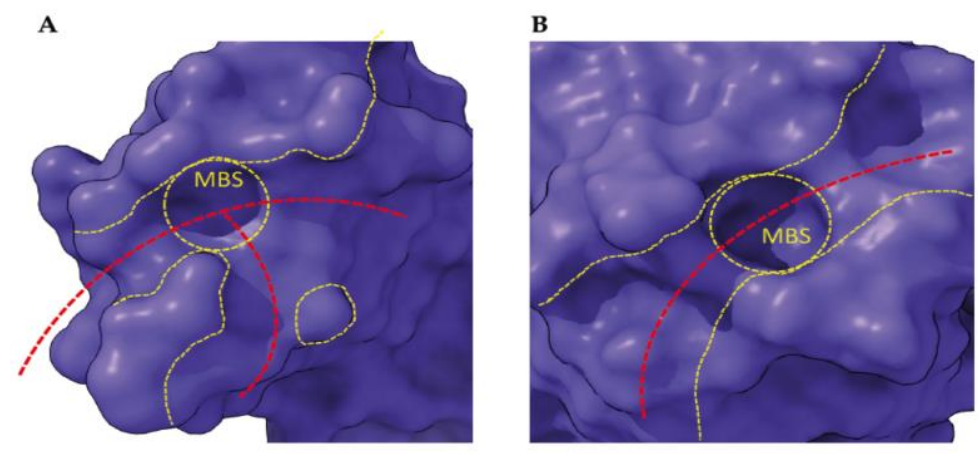

Figure 6. Molecular surface of the top of HPA (A) and Morniga G (B) monomer: The topographical organization of the surface surrounding the monosaccharide-binding site/pocket (delineated by a yellow dashed circle) is shown. The red dashed lines define the axes along which additional sugar units linked to the sugar occupying the monosaccharide-binding site (MBS) could be accommodated by hydrophilic and hydrophobic residues forming the extended CBS located around the MBS. The regions surrounding the MBS susceptible to accommodating branched $O$-glycans are delineated by yellow dashed lines.

\section{Discussion}

In this paper we demonstrated for the first time that the Helix pomatia lectin, commonly used in the diagnosis of various cancers [11,29-32], can kill human T lymphocyte leukemia and mouse T lymphoma. Using the human Jurkat cell leukemia, the level of HPA-induced cell death was similar to that with Morniga G-induced cell death. Morniga G was previously demonstrated to induce cell death in cell leukemias expressing Tn antigen but not in healthy lymphocytes [15], probably because naive or resting T-lymphocytes are Tn negative [37,38]. In the Jurkat human T cell leukemia, HPA could trigger cell death pathways similar to Morniga $G$, most likely after interaction with membrane glycoproteins carrying altered O-glycans, i.e., Tn antigen, strongly expressed by Jurkat $\mathrm{T}$ cells $[14,15]$ but not by healthy resting T lymphocytes [15,38]. Interestingly, $2.5 \mu \mathrm{g} / \mathrm{mL}(0.032 \mathrm{nM}) \mathrm{HPA}$ is clearly more efficient than same concentration of Morniga $G$ to induce cell death in mouse $T$ lymphoma (Figures $2 \mathrm{~B}$ and $4 \mathrm{D}$ ), and this result was confirmed in assays with a mixture of EL4 T lymphoma cells + normal lymphocytes (Figure 3C,D). Furthermore, HPA and Morniga $\mathrm{G}$ induce different quantitative modifications in CD3-positive and -negative lymphocyte populations (Figure 3D), indicating that the two lectins displaying similar sugar-binding specificities towards simple sugars (i.e., to the GalNAc) might present various biological effects on tumor cells and normal cells, at least partly because the two lectins could exhibit distinct binding affinities with different oligosaccharides incorporating GalNAc (or galactose). However, a role for structural differences between HPA and Morniga G cannot be excluded. Indeed, HPA is a hexameric lectin with six possible CRDs [35]), whereas Morniga $G$ is a tetrameric lectin with only four CRDs [36]. Evidently, a lectin molecule with a higher number of CRDs can interact with more membrane glycoproteins and this could be an advantage for cell signal induction by facilitating receptor clustering, lattice formation on the cell surface, and triggering of downstream signaling, for instance to induce cell death.

As indicated above, both HPA and Morniga G are known as Tn-specific lectins. Consequently, HPA-induced cell death in Jurkat leukemia could be due to lectin binding to Tn antigen overexpressed on the cell surface, and at least partly due to the Tn-antigenmodified DR5 (TRAIL receptor) as previously shown for Morniga G [15]. In agreement with the programmed cell death characteristics observed in the present study (Figure 1B-D), it can be speculated that the induction of apoptosis by HPA is possibly due to DR5 clustering triggered by lectin binding to the surface glycans of Jurkat cells.

It was previously demonstrated that EL4 cells exhibit higher levels of sialic acids on the cell membrane compared to normal T cells [33]. Our results indicated that HPA-induced cell death is not significantly affected by the presence of sialic acid on EL4 cells, in spite 
of the fact that moderate inhibition of HPA-binding to the EL4 cells correlated with the surface hypersialylation, suggesting that HPA-mediated cell death is largely independent of the presence of sialic acid.

In addition, the present results indicated that the aberrant synthesis of large quantities of T/Tn antigens by EL-4 lymphoma must be ruled out, suggesting that an increase of $O$-glycan Core 1 (i.e., T antigen), cannot be the target for HPA on the EL4 cell membrane. However, other truncated O-glycan alterations could be possible targets for HPA, resulting in induction of cell death. For instance, it is possible HPA recognizes high Core 2 (GlcNAc $\beta 1-6(\mathrm{Gal} \beta 1-3)$ GalNAc $\alpha$ Ser/Thr) or Core 3 (GlcNAc $\beta 1-6$ GalNAc $\alpha$ Ser/Thr) expression on EL4 cells because the lectin has previously been reported as GlcNAc-specific [34,39], whereas Morniga $G$ is not known for this. In addition, our comparative bioinformatic modeling of Morniga G and HPA suggest that in contrast to Morniga G, the HPA molecule should offer more possibilities for binding to branched O-glycans. Further experiments will need to be performed to demonstrate the involvement of Core 2 or Core 3 structures in HPA-mediated cell death.

Truncated O-glycans can strongly modulate T-cell function. Thus, beside the glycosylation on death receptors (such like DR5, DR4, or Fas) altered O-glycans carried by other glycoproteins can also be involved as possible targets for HPA. Indeed, numerous glycoproteins decorated by O-glycans are expressed on EL4 lymphoma [40,41], could be recognized by HPA and potentially involved in induction of cell death [42]. For instance, CD43 and CD45 glycoproteins are expressed by EL4 cells and carry many O-glycans [41]. In agreement with numerous observations, these cell-surface glycoproteins can be involved in cell death. CD43 and CD45 molecules are known to play a major role in T lymphocyte physiology [43]. The abundance and the structure of the O-glycans decorating CD45 and CD43 are modulated during activation and survival of T lymphocytes, and participate in the regulation of the life-span of $\mathrm{T}$ lymphocytes. For instance, activated $\mathrm{T}$ lymphocytes express CD45 carrying O-glycan Core 2 instead of $O$-glycan Core 1 that is present on naive $\mathrm{T}$ lymphocytes (i.e., $\mathrm{T}$ antigen) [44]. As a consequence of this change in O-glycosylation, the susceptibility to cell death inducers is modulated [43]. For instance, activated T lymphocytes become sensitive to galectin1-induced apoptosis [44] as compared to naive lymphocytes. Because certain surface markers of activated T-cells are also present on EL4 cells, this tumoral cell line could possibly be rich in Core $2 \mathrm{O}$-glycans and, from this point of view, more sensitive to HPA-induced cell death than naive T lymphocytes.

Although still poorly known, quantitative and qualitative modulations of $O$-glycans on the cell surface are normal phenomena in lymphocyte physiology $[18,38,43]$. The expression of truncated $O$-glycans on tumor cells could disturb the efficiency of anti-tumor immune responses. However, healthy naive T lymphocytes are Tn-negative, allowing the development of therapeutic targeting to eliminate Tn-positive tumor cells, or expressing other types of truncated $\mathrm{O}$-glycans (such as Core $2 \mathrm{O}$-glycan). For instance, previously, in vitro experiments demonstrated that covalent conjugation of photosensitizers with MorG allows targeting towards aberrant glycans present on tumor cells, e.g., to purge leukemia cells from blood [45]. Several studies have indicated the possibility of using HPA and other H-type lectins for the specific delivery of drugs in tumor cells, e.g., for in vitro drug delivery to breast cancer cells [46]. However, to our knowledge, in vivo investigations using HPA (or MorG) have not been carried out to date in animal pre-clinical models.

\section{Materials and Methods}

\subsection{Cell Cultures}

Jurkat A3 human T-cell leukemia line (from ATCC, Manassas, VA, USA) was cultured in RPMI medium containing 10\% FCS. EL4 mouse T-cell lymphoma line (ATCC, Manassas, VA, USA) was cultured in DMEM medium containing $10 \%$ FCS. Mouse splenocytes were extracted from C57BL/6 mice in DMEM medium, then splenocytes were incubated in DMEM medium on a Petri dish for two hours at $37^{\circ} \mathrm{C}$, to obtain non-adherent mouse splenocytes. C57BL/6 mice were a gift from Dr. A. Coste (UPS Toulouse University, 
Toulouse, France) and from the Anexplo platform. Mice were housed in temperaturecontrolled rooms in the specific pathogen-free animal facility (Anexplo platform, Toulouse, France), kept on a $12 \mathrm{~h}$ light/dark cycle, and had unrestricted access to food and water. All animal studies were conducted according to national and international policies.

\subsection{Lectin-Mediated Cytotoxicity Assay and Cell Death Evaluation}

HPA, Concanavalin A (Con A), and FITC-Con A were purchased from Sigma-Aldrich (Saint-Louis, MO, USA). FITC-HPA was purchased from Invitrogen (Carlsbad, CA, USA). Morniga-G (MorG) and Artocarpin (MorM) were purified from Morus nigra and Artocarpus integrifolia, respectively, as previously described [26,27]. Artocarpin and Morniga-G were labelled with FITC (Amersham Biosciences, Amersham, UK)

Jurkat A3 cells and EL4 cells were treated with Morniga-G, HPA, Artocarpin, and Concavalin A lectins for $48 \mathrm{~h}$ in RPMI or DMEM supplemented with SVF $10 \%$ at $37^{\circ} \mathrm{C} / 5 \%$ $\mathrm{CO}_{2}$ humidified atmosphere. Cell death was estimated by flow cytofluorometry analysis with Muse Annexin V and Dead Cell Assay kit (\#MCH100105) using MUSE cell analyzer (Luminex Corporation, Austin, TX, USA). Cell death was also evaluated by fluorescent microscopy using DAPI death marker (\#564907 BD Bioscience, Franklin Lakes, NJ, USA).

For mitochondrial membrane depolarization, cells were cultivated with lectins for $48 \mathrm{~h}$ and mitochondrial membrane potential (mitopotential) was analyzed using Muse MitoPotential Kit (\#MCH100110) (Luminex Corporation, Austin, TX, USA) and Muse Cells Analyzer. Caspase activation were analyzed by Muse MultiCaspase Kit (\#MCH100109).

\subsection{Preparation of Healthy Lymphocytes and EL4 Mixtures}

Non-adherent splenocytes, i.e., T, B, and NK lymphocytes, were prepared from C57BL6 mice as described above. EL4 cells were labeled with 1 $\mathrm{gg} / \mathrm{mL}$ CFSE (\#65-0850-84 Invitrogen, Carlsbad, CA, USA) for $1 \mathrm{~h}$ and washed. Afterwards a mixture (1:1) was prepared with lymphocytes and CFSE-labeled EL4 cells in DMEM supplemented with SVF 10\%. The mixture was cultured for $48 \mathrm{~h}$ in the presence of $20 \mu \mathrm{g} / \mathrm{mL}$ Morniga G or HPA. After washing, wells were incubated with PE-labelled anti-CD3 mouse monoclonal antibody (Becton Dickinson; Franklin Lakes, NJ, USA) and analyzed using cytofluorimetry.

\subsection{Cell Surface-Binding Experiments}

Cells $\left(10^{6} / \mathrm{mL}\right)$ were incubated with FITC-Lectins $(0.01$ to $5 \mu \mathrm{g} / \mathrm{mL})$, anti-Tn (antiCD175), or anti-T (anti-CD176) mouse monoclonal antibodies (mAb) $(1 \mu \mathrm{g} / \mathrm{mL})$ (\#MA190544 Invitrogen, Carlsbad, CA, USA) for $30 \mathrm{~min}$ at $4{ }^{\circ} \mathrm{C}$ in PBS. After incubation with $\mathrm{mAb}$, cells were washed and stained with PE-conjugated secondary antibody (BD Bioscience) for $30 \mathrm{~min}$ at $4{ }^{\circ} \mathrm{C}$ in PBS. After washing, cells were analyzed using Fortessa FACS (BD Bioscience) flow cytometer. 7-AAD Viability Staining Solution (\#00-6993-50 Invitrogen, Carlsbad, CA, USA) was added to exclude dead cells.

\subsection{Neuraminidase Treatment of EL4 Cells}

EL4 cells were treated with 20 mUI Neuraminidase (\#E0540S New England Biolabs, Ipswich, MA, USA) for $30 \mathrm{~min}$ at $37^{\circ} \mathrm{C}$ in PBS, then washed before using.

\subsection{ROS Detection}

EL4 cells were exposed to HPA or Concanavalin A lectins in DMEM supplemented with SVF $10 \%$ at $37^{\circ} \mathrm{C} / 5 \% \mathrm{CO}_{2}$ humidified atmosphere. ROS production was analyzed by Muse Oxidative Stress Kit (\#MCH100111) or Muse Nitric Oxide Kit (\#MCH100112) using Muse Cells Analyzer. ROS were also analyzed by dihydroethidium (DHE) fluorescent probe using Fortessa FACS (BD Bioscience, Franklin Lakes, NJ, USA). 


\subsection{Statistical Analyses}

Results are expressed as the means \pm SD of data obtained from at least three independent experiments. Statistical significance was determined by means of Student's $t$-test. $p<0.05$ was considered significant.

\subsection{In Silico Molecular Modeling and Docking Experiments}

Homology modelling of Morniga-G, was performed with YASARA [47], using the Xray coordinates of frutalin from Artocarpus incisa (PDB code 4 WOG), jacalin from Artocarpus heterophyllus (PDB code 3P8S), the Maclura pomifera agglutinin MPA (PDB code 3LLZ) [48], and agglutinin a-chain from Artocarpus integer (PDB codes 1UGX and 4AK4) [49,50], as templates. Five different models were built for Morniga- $G$ and finally, a single hybrid model was built up from the previous models. PROCHECK [51], ANOLEA [52], and the calculated QMEAN scores [53,54], were used to assess the geometric and thermodynamic qualities of the Morniga-G three-dimensional model. A single amino acid residue D163 on a total of 166 residues, occurred in the non-allowed regions in the Ramachandran plot. Using ANOLEA to evaluate the Morniga-G model, only 17 residues (out of 166) exhibited an energy over the threshold value. The calculated QMEAN score gave an acceptable value of 0.96. The three-dimensional structure of Helix pomatia agglutinin (HPA) was taken from the PDB (PDB code 2CE6 for the unliganded lectin, PDB codes 2CCV for HPA in complex with GalNAc and 2CGZ for HPA in complex with Tn antigen) [36,55].

Docking of GalNAc, GlcNAc, and Tn antigen was performed with YASARA. Some docking experiments were performed at the SwissDock web server (http: / www.swissdock. ch, accessed on 21 May 2021) [56,57], as a control for our docking experiments. Molecular cartoons were drawn with Chimera [58] and Chimera-X [59].

\section{Conclusions}

In conclusion, comparative experiments with Morniga G and HPA, two exogenous lectins known to be T/Tn-specific, demonstrated similar effects on Tn-positive leukemic lymphocytes. However, only HPA killed T/Tn-negative T lymphoma cells efficiently without affecting healthy lymphocytes. This observation suggests that HPA is not only a good tool as cancer marker, but could also be used for therapeutic applications.

Author Contributions: M.S. and H.B. conceived and designed the experiments; M.S. and Y.B. performed the experiments; A.B. and P.R. performed the in silico computer simulations; E.J.M.V.D. contributed Morniga-G and Artocarpin lectins; M.S., P.R., and H.B. wrote the paper; A.B. and E.J.M.V.D. improved and corrected the style of the article. H.B. supervised the work. All authors have read and agreed to the published version of the manuscript.

Funding: This research received no external funding.

Institutional Review Board Statement: The study was conducted according to the guidelines of the Declaration of Helsinki, and approved by CREFRE, Inserm-UT3 Paul Sabatier US 006 (ethic code/project number: Apafis \#16130-2018071609594632).

Informed Consent Statement: Not applicable.

Data Availability Statement: Data is contained within the article.

Conflicts of Interest: The authors declare no conflict of interest.

\section{References}

1. Divya, T.; Ashok, K.R.; Prakash, R. Altered glycosylation in cancer: A promising target for biomarkers and therapeutics. Biochim. Biophys. Acta Rev. Cancer 2021, 1875, 188464.

2. Dall'Olio, F.; Trinchera, M. Epigenetic bases of aberrant glycosylation in cancer. Int. J. Mol. Sci. 2017, 18, 998. [CrossRef] [PubMed]

3. Ihara, S.; Miyoshi, E.; Ko, J.H.; Murata, K.; Nakahara, S.; Honke, K.; Dickson, R.B.; Lin, C.Y.; Taniguchi, N. Prometastatic effect of $\mathrm{N}$-acetylglucosaminyltransferase $\mathrm{V}$ is due to modification and stabilization of active matriptase by adding beta 1-6 GlcNAc branching. J. Biol. Chem. 2002, 277, 16960-16967. [CrossRef] 
4. Ju, T.; Lanneau, G.S.; Gautam, T.; Wang, Y.; Xia, B.; Stowell, S.R.; Willard, M.T.; Wang, W.; Xia, J.Y.; Zuna, R.E.; et al. Human tumor anti- gens Tn and sialyl Tn arise from mutations in Cosmc. Cancer Res. 2008, 68, 1636-1646. [CrossRef] [PubMed]

5. Carrascal, M.A.; Severino, P.F.; Guadalupe Cabral, M.; Silva, M.; Ferreira, J.A.; Calais, F.; Quinto, H.; Pen, C.; Ligeiro, D.; Santos, L.L.; et al. Sialyl Tn-expressing bladder cancer cells induce a tolerogenic phenotype in innate and adaptive immune cells. Mol. Oncol. 2014, 8, 753-765. [CrossRef]

6. Marcos, N.T.; Pinho, S.; Grandela, C.; Cruz, A.; Samyn-Petit, B.; Harduin-Lepers, A.; Almeida, R.; Silva, F.; Morais, V.; Costa, J.; et al. Role of the human ST6GalNAc-I and ST6GalNAc-II in the synthesis of the cancer-associated sialyl-Tn antigen. Cancer Res. 2004, 64, 7050-7057. [CrossRef] [PubMed]

7. Rodrigues, E.; Macauley, M.S. Hypersialylation in Cancer: Modulation of Inflammation and Therapeutic Opportunities. Cancers 2018, 10, 207. [CrossRef] [PubMed]

8. Ferreira, J.A.; Videira, P.A.; Lima, L.; Pereira, S.; Silva, M.; Carrascal, M.; Severino, P.F.; Fernandes, E.; Almeida, A.; Costa, C.; et al. Overexpression of tumour-associated carbohydrate antigen sialyl-Tn in advanced bladder tumours. Mol. Oncol. 2013, 7, 719-731. [CrossRef]

9. Sinha, D.; Mandal, C.; Bhattacharya, D.K. Identification of 9-O acetyl sialoglycoconjugates (9-OAcSGs) as biomarkers in childhood acute lymphoblastic leukemia using a lectin, AchatininH, as a probe. Leukemia 1999, 13, 119-125. [CrossRef]

10. Ma, H.; Zhou, H.; Song, X.; Shi, S.; Zhang, J.; Jia, L. Modification of sialylation is associated with multidrug resistance in human acute myeloid leukemia. Oncogene 2015, 34, 726-740. [CrossRef]

11. Laack, E.; Nikbakht, H.; Peters, A.; Kugler, C.; Jasiewicz, Y.; Edler, L.; Hossfeld, D.K.; Schumacher, U. Lectin histochemistry of resected adenocarcinoma of the lung: Helix pomatia agglutinin binding is an independent prognostic factor. Am. J. Pathol. 2002, 160, 1001-1008. [CrossRef]

12. Poiroux, G.; Barre, A.; van Damme, E.J.M.; Benoist, H.; Rougé, P. Plant lectins targeting O-glycans at the cell surface as tools for cancer diagnostic, pronostic and therapy. Int. J. Mol. Sci. 2017, 18, 1232. [CrossRef] [PubMed]

13. Gill, D.J.; Tham, K.M.; Chia, J.; Wang, S.C.; Steentoft, C.; Clausen, H.; Bard-Chapeau, E.A.; Bard, F.A. Initiation of GalNAc-type O-glycosylation in the endoplasmic reticulum promotes cancer cell invasiveness. Proc. Natl. Acad. Sci. USA 2013, 110, 3152-3161. [CrossRef]

14. Jiang, Y.; Wen, T.; Yan, R.; Kim, S.R.; Stowell, S.R.; Wang, W.; Wang, Y.; An, G.; Cummings, R.D.; Ju, T. O-glycans on death receptors in cells modulate their sensitivity to TRAIL-induced apoptosis through affecting on their stability and oligomerization. FASEB J. 2020, 34, 11786-11801. [CrossRef]

15. Poiroux, G.; Barre, A.; Simplicien, M.; Pelofy, S.; Segui, B.; Van Damme, E.J.M.; Rougé, P.; Benoist, H. Morniga-G, a T/Tn-Specific Lectin, Induces Leukemic Cell Death via Caspase and DR5 Receptor-Dependent Pathways. Int. J. Mol. Sci. 2019, $20,230$. [CrossRef] [PubMed]

16. Wagner, K.W.; Punnoose, E.A.; Januario, T.; Lawrence, D.A.; Pitti, R.M.; Lancaster, K.; Lee, D.; von Goetz, M.; Yee, S.F.; Totpal, K.; et al. Death-receptor $\mathrm{O}$-glycosylation controls tumor-cell sensitivity to the proapoptotic ligand Apo2L/TRAIL. Nat. Med. 2007, 13, 1070-1077. [CrossRef]

17. Dufour, F.; Rattier, T.; Shirley, S.; Picarda, G.; Constantinescu, A.A.; Morle, A.; Zakaria, A.B.; Marcion, G.; Causse, S.; Szegezdi, E.; et al. N-glycosylation of mouse TRAIL-R and human TRAIL-R1 enhances TRAIL-induced death. Cell Death Differ. 2017, 24, 500-510. [CrossRef]

18. Rabinovich, G.A.; van Kooyk, Y.; Cobb, B.A. Glycobiology of immune responses. Ann. N.Y. Acad. Sci. 2012, 1253, 1-15. [CrossRef]

19. Seyrek, K.; Richter, M.; Lavrik, I.N. Decoding the sweet regulation of apoptosis: The role of glycosylation and galectins in apoptotic signaling pathways. Cell Death Differ. 2019, 26, 981-993. [CrossRef] [PubMed]

20. Bhutia, S.K.; Panda, P.K.; Sinha, N.; Praharaj, P.P.; Bhol, C.S.; Panigrahi, D.P.; Mahapatra, K.K.; Saha, S.; Patra, S.; Mishra, S.R.; et al. Plant lectins in cancer therapeutics: Targeting apoptosis and autophagy-dependent cell death. Pharmacol. Res. 2019, 44, 8-18. [CrossRef]

21. Takayama, H.; Ohta, M.; Iwashita, Y.; Uchida, H.; Shitomi, Y.; Yada, K.; Inomata, M. Altered glycosylation associated with dedifferentiation of hepatocellular carcinoma: A lectin microarray-based study. BMC Cancer 2020, 20, 192. [CrossRef] [PubMed]

22. Zhao, Q.; Zhan, T.; Deng, Z.; Li, Q.; Liu, Y.; Yang, S.; Ji, D.; Li, Y. Glycan analysis of colorectal cancer samples reveals stagedependent changes in CEA glycosylation patterns. Clin. Proteom. 2018, 15, 9. [CrossRef] [PubMed]

23. He, J.; Liu, Y.; Zhu, T.S.; Xie, X.; Costello, M.A.; Talsma, C.E.; Flack, C.G.; Crowley, J.G.; Dimeco, F.; Vescovi, A.L.; et al. Glycoproteomic analysis of glioblastoma stem cell differentiation. J. Proteome Res. 2011, 10, 330-338. [CrossRef]

24. Benoist, H.; Culerrier, R.; Poiroux, G.; Ségui, B.; Jauneau, A.; Van Damme, E.J.; Peumans, W.J.; Barre, A.; Rougé, P. Two structurally identical mannose-specific jacalin-related lectins display different effects on human T lymphocyte activation and cell death. J. Leukoc. Biol. 2009, 86, 103-114. [CrossRef]

25. Tejero, J.; Jiménez, P.; Quinto, E.J.; Cordoba-Diaz, D.; Garrosa, M.; Cordoba-Diaz, M.; Gayoso, J.; Girbés, T. Elderberries: A source of ribosome-inactivating proteins with lectin activity. Molecules 2015, 20, 2364-2387. [CrossRef]

26. Tsai, M.-H.; Liu, J.-F.; Chiang, Y.-C.; Hu, S.C.-S.; Hsu, L.-F.; Lin, Y.-C.; Lin, Z.-C.; Lee, H.-C.; Chen, M.-C.; Huang, C.-L.; et al. Artocarpin, an isoprenyl flavonoid, induces p53-dependent or independent apoptosis via ROS-mediated MAPKs and Akt activation in non-small cell lung cancer cells. Oncotarget 2017, 8, 28342-28358. [CrossRef] 
27. Singh, T.; Wu, J.H.; Peumans, W.J.; Rougé, P.; Van Damme, E.J.; Wu, A.M. Recognition profile of Morus nigra agglutinin (Morniga G) expressed by monomeric ligands, simple clusters and mammalian polyvalent glycotopes. Mol. Immunol. 2007, 44, 451-462. [CrossRef]

28. Pietrzyk-Brzezinska, A.J.; Bujacz, A. H-type lectins-Structural characteristics and their applications in diagnostics, analytics and drug delivery. Int. J. Biol. Macromol. 2020, 152, 735-747. [CrossRef]

29. Peiris, D.; Ossondo, M.; Fry, S.; Loizidou, M.; Smith-Ravin, J.; Dwek, M.V. Identification of O-Linked Glycoproteins Binding to the Lectin Helix pomatia Agglutinin as Markers of Metastatic Colorectal Cancer. PLoS ONE. 2015, 10, e0138345. [CrossRef] [PubMed]

30. Milde-Langosch, K.; Schütze, D.; Oliveira-Ferrer, L.; Wikman, H.; Müller, V.; Lebok, P.; Pantel, K.; Schröder, C.; Witzel, I.; Schumacher, U. Relevance of $\beta$ Gal- $\beta$ GalNAc-containing glycans and the enzymes involved in their synthesis for invasion and survival in breast cancer patients. Breast Cancer Res. Treat. 2015, 151, 515-528. [CrossRef] [PubMed]

31. Thöm, I.; Schult-Kronefeld, O.; Burkholder, I.; Goern, M.; Andritzky, B.; Blonski, K.; Kugler, C.; Edler, L.; Bokemeyer, C.; Schumacher, U.; et al. Lectin histochemistry of metastatic adenocarcinomas of the lung. Lung Cancer 2007, 56, 391-397. [CrossRef] [PubMed]

32. Thies, A.; Moll, I.; Berger, J.; Schumacher, U. Lectin binding to cutaneous malignant melanoma: HPA is associated with metastasis formation. Br. J. Cancer 2001, 84, 819-823. [CrossRef]

33. Alaeddine, M.; Prat, M.; Poinsot, V.; Gouazé-Andersson, V.; Authier, H.; Meunier, E.; Lefèvre, L.; Alric, C.; Dardenne, C.; Bernad, J.; et al. IL13-Mediated Dectin-1 and Mannose Receptor Overexpression Promotes Macrophage Antitumor Activities through Recognition of Sialylated Tumor Cells. Cancer Immunol. Res. 2019, 7, 321-334. [CrossRef]

34. Rambaruth, N.D.S.; Greenwell, P.; Dwek, M.V. The lectin Helix pomatia agglutinin recognizes O-GlcNAc containing glycoproteins in human breast cancer. Glycobiology 2012, 22, 839-848. [CrossRef]

35. Sanchez, J.-F.; Lescar, J.; Chazalet, V.; Audfray, A.; Gagnon, J.; Alvarez, R.; Breton, C.; Imberty, A.; Mitchell, E.P. Biochemical and structural analysis of Helix pomatia agglutinin. A hexameric lectin with a novel fold. J. Biol. Chem. 2006, 281, 20171-20180. [CrossRef] [PubMed]

36. Rougé, P.; Peumans, W.J.; Van Damme, E.J.M.; Barre, A.; Singh, T.; Wu, J.H.; Wu, A.M. Glycotope structures and intramolecular affinity factors of plant lectins for T/Tn antigens. Adv. Exp. Med. Biol. 2011, 705, 143-154.

37. Cutler, C.E.; Jones, M.B.; Cutler, A.A.; Mener, A.; Arthur, C.M.; Stowell, S.R.; Cummings, R.D. Cosmc is required for T cell persistence in the periphery. Glycobiology 2019, 29, 776-788. [CrossRef]

38. Shi, C.; Xu, X.; Yu, X.; Du, Z.; Luan, X.; Liu, D.; Hu, T. CD3/CD28 dynabeads induce expression of Tn antigen in human T cells accompanied by hypermethylation of the cosmc promoter. Mol. Immunol. 2017, 90, 98-105. [CrossRef]

39. Brooks, S.A.; Carter, T.M. $N$-acetylgalactosamine, $N$-acetylglucosamine and sialic acid expression in primary breast cancers. Acta Histochem. 2001, 103, 37-51. [CrossRef] [PubMed]

40. Gays, F.; Unnikrishnan, M.; Shrestha, S.; Fraser, K.P.; Brown, A.R.; Tristram, C.M.G.; Chrzanowska-Lightowlers, Z.M.A.; Brooks, C.G. The mouse tumor cell lines EL4 and RMA display mosaic expression of NK-related and certain other surface molecules and appear to have a common origin. J. Immunol. 2000, 164, 5094-5102. [CrossRef] [PubMed]

41. Kovar, L.; Etrych, T.; Kabešová, M.; Subr, V.; Vetvicka, D.; Hovorka, O.; Strohalm, J.; Sklenar, J.; Chytil, P.; Ulbrich, K.; et al. Doxorubicin attached to HPMA copolymer via amide bond modifies the glycosylation pattern of EL4 cells. Tumor Biol. 2010, 31, 233-242. [CrossRef]

42. Rajasagi, M.; von Au, A.; Singh, R.; Hartmann, N.; Zöller, M.; Marhaba, R. Anti-CD44 induces apoptosis in T lymphoma via mitochondrial depolarization. J. Cell. Mol. Med. 2010, 14, 1453-1467. [CrossRef]

43. Clark, M.C.; Baum, L.G. T cells modulate glycans on CD43 and CD45 during development and activation, signal regulation, and survival. Ann. N.Y. Acad. Sci. 2012, 1253, 58-67. [CrossRef]

44. Earl, L.A.; Bi, S.; Baum, L.G. N- and O-glycans modulate galectin-1 binding, CD45 signaling, and T cell death. J. Biol. Chem. 2010, 285, 2232-2244. [CrossRef]

45. Poiroux, G.; Pitié, M.; Culerrier, R.; Lafont, E.; Ségui, B.; Van Damme, E.J.M.; Peumans, W.J.; Bernadou, J.; Levade, T.; Rougé, P.; et al. Targeting of $\mathrm{T} / \mathrm{Tn}$ antigens with a plant lectin to kill human leukemia cells by photochemotherapy. PLoS ONE 2011, 6, 23315. [CrossRef]

46. Madani, S.Y.; Tan, A.; Dwek, M.; Seifalian, A.M. Functionalization of single-walled carbon nanotubes and their binding to cancer cells. Int. J. Nanomed. 2012, 7, 905-914.

47. Krieger, E.; Koraimann, G.; Vriend, G. Increasing the precision of comparative models with YASARA NOVA-A self-parametrizing force field. Proteins 2002, 47, 393-402. [CrossRef]

48. Huang, J.; Xu, Z.; Wang, D.; Ogata, C.M.; Palczewski, K.; Lee, X.; Young, N.M. Characterization of the secondary binding sites of Maclura pomifera agglutinin by glycan array and crystallographic analyses. Glycobiology 2010, 20, 1643-1653. [CrossRef]

49. Jeyaprakash, A.A.; Katyar, S.; Swaminathan, C.P.; Sekar, K.; Surolia, A.; Vijayan, M. Structural basis of the carbohydrate specificities of jacalin: An X-ray and modeling study. J. Mol. Biol. 2003, 332, 217-228. [CrossRef]

50. Gabrielsen, M.; Abdul-Rahman, P.S.; Othman, S.; Hashim, O.H.; Cogdell, R.J. Structures and binding specificity of galactose- and mannose-binding lectins from champedak: Differences from jackfruit lectins. Acta Crystallogr. F Struct. Biol. Commun. 2014, 70, 709-716. [CrossRef]

51. Laskowski, R.A.; MacArthur, M.W.; Moss, D.S.; Thornton, J.M. PROCHECK: A program to check the stereochemistry of protein structures. J. Appl. Crystallogr. 1993, 126, 283-291. [CrossRef] 
52. Melo, F.; Feytmans, E. Assessing protein structures with a non-local atomic interaction energy. J. Mol. Biol. 1998, $277,1141-1152$. [CrossRef]

53. Benkert, P.; Biasini, M.; Schwede, T. Toward the estimation of the absolute quality of individual protein structure models. Bioinformatics 2011, 27, 343-350. [CrossRef] [PubMed]

54. Arnold, K.; Bordoli, L.; Kopp, J.; Schwede, T. The SWISS-MODEL workspace: A web-based environment for protein structure homology modelling. Bioinformatics 2006, 22, 195-201. [CrossRef] [PubMed]

55. Lescar, J.; Sanchez, J.-F.; Audfray, A.; Coll, J.-L.; Breton, C.; Mitchell, E.P.; Imberty, A. Structural basis for recognition of breast and colon cancer epitopes Tn antigen and Forssman disaccharide by Helix pomatia lectin. Glycobiology 2007, 17, 1077-1083. [CrossRef] [PubMed]

56. Grosdidier, A.; Zoete, V.; Michielin, O. SwissDock, a protein-small molecule docking web service based on EADock DSS. Nucleic Acids Res. 2011, 39, W270-W277. [CrossRef]

57. Grosdidier, A.; Zoete, V.; Michielin, O. Fast docking using the CHARMM force field with EADock DSS. J. Comput. Chem. 2011, 32, 2149-2159. [CrossRef]

58. Pettersen, E.F.; Goddard, T.D.; Huang, C.C.; Couch, G.S.; Greenblatt, D.M.; Meng, E.C.; Ferrin, T.E. UCSF Chimera-A visualization system for exploratory research and analysis. J. Comput. Chem. 2004, 25, 1605-1612. [CrossRef]

59. Goddard, T.D.; Huang, C.C.; Meng, E.C.; Pettersen, E.F.; Couch, G.S.; Morris, J.H.; Ferrin, T.E. UCSF ChimeraX: Meeting modern challenges in visualization and analysis. Protein Sci. 2018, 27, 14-25. [CrossRef] 